\title{
PENELITIAN PENGARUH PENGGUNAAN RIKLIM \\ POLIETILEN TERHADAP SIFAT KETAHANAN PUKUL DAN KEKERASAN
}

\author{
Oleh : Supraptiningsih dan Sofyan Karani
}

\section{ABSTRACT}

The aim of this research is to know further about the influence of polyethylene reclaim to the characteristic of impact resistance and high density polyethylene (HDPE) compound.

The research is done by making HDPE compound with the addition of polyethylene reclaim with various procentage of quantity.

In fact the addition on of HDPE reclaim into pure HDPE doesn't influence the hardness of the compound produced, but it influence the impact resistance to signification phase $P 0,05$ by linear aquation $Y=10,26+0,0887$.

The compound hardness is approximately $63,2-64,0$ shore $\mathrm{U}$, and impact resistance is approximately $10,83-18,91 \mathrm{~kg}$ $\mathrm{cm} / \mathrm{cm}$ in various variation.

\section{PENDAHULUAN}

\section{Latar Belakang.}

Peningkatan limbah plastik telah menimbulkan dampak negatif terhadap lingkungan hidup, mengingat sifat plastik tidak membusuk, tidak terurai secara alami, tidak menyerap air dan tidak berkarat.

Plastik buangan yang telah dibuat pellet dapat digunakan sebagai pencampur atau bahan pengisi plastik yang kemudian disebut riklim. Pencampuran riklim dengan plastik murni akan mengurangi mutu barang yang dihasilkan.

Sejauh mana pencampuran bahan riklim akan mempengaruhi sifat ketahanan pukul dan sifat kekerasan pada kompon plastik yang dihasilkan memerlukan penelitian. 
Apabila telah terlihat hubungan antara penambahan jumlah riklim polietilen ke dalam resin polietilen dengan sifat fisikanya maka akan dengan mudah menentukan jumlah penam bahan riklim pada barang jadi plastik polietilen yang dii nginkan.

\section{Tujuan Penelitian.}

Untuk mengetahui seberapa jauh pengaruh riklim polietilen terhadap sifat ketahanan pukul dan kekerasan.

\section{Sasaran Penelitian.}

Mendapatkan kompon polietilen.

\section{IINJAUAN PUSTAKA}

Plastik thermoplast tidak membentuk jaringan tiga dimensi, sehingga akan menjadi keras setelah pendinginan. Plastik ini dapat dibuat lunak kembali oleh adanya panas dan dapat dicetak ulang.

Hal ini merupakan suatu keuntungan karena barang-barang Hal ini merupakan suatu keunbali dengan menjadikan bentuk

plastik bekas dapat diproses kembali den

Bahan plastik ini dapat ditambah berbagai additiv agar sesuai dengan teknik pengolahan yang dipakai dan aplikasinya. Berbagai bahan plastik yang termasuk golongan thermoplastik adalah : polipropilon, polietilen, polivinyl chlorida, polyasetat, dll.

Polietilen merupakan hasil reaksi polimerisasi dari monomerethylen. Jika polimerisasi etilen dilaksanakan pada tekanan tinggi akan menghasilkan Low Density Polietilen (LDPE), sedangkan jika dilaksanakan pada tekanan yang relatif rendah akan menghasilkan High Density Polietilen (HDPE).

Polietilen dapat diproses dengan metode injection molding, extrusion blow molding, coating, foaming dan produk yang dihasilkan berupa barang-barang cetak, film, karung plastik, mainan anak-anak, botol jerigen, tali tambang dan bunga. (4). Hypotesa.

Penambahan riklim polietilen ke dalam kompon polietilen akan menurunkan sifat-sifat fisis kompon.

\section{MATERI DAN METODE PENELITIAN}

A. Materi.

Bahan-bahan.

- High Density Polietilen (HDPE).

- Riklim Polietilen.

Alat-alat.

neraca analitis, banbury mixer, hydroulic test press, shore durometer hardness tester, universal impact tester, plastik cutting instruments, micrometer.

B. Prosedur Penelitian.

Pencampuran HDPE dengan riklim polietilen yang keduanya berbentuk "granular" menggunakan mesin banbury mixer dengan kondisi proses suhu $60^{\circ} \mathrm{C}$, waktu 5 menit, kecepatan $16 \mathrm{rpm}$ dan tekanan $4-7 \mathrm{~kg} / \mathrm{cm}^{2}$.

Hasil campuran HDPE dengan riklim polietilen dibuat slab contoh vji dengan menggunakan alat hydroulic test press dengan kondisi proses suhu $180^{\circ} \mathrm{C}$, tekanan $150 \mathrm{~kg} / \mathrm{cm}^{2}$ dan waktu 25 menit termasuk pra pemanasan 15 menit.

\section{Pengujian.}

Pengujian hasil penelitian dilakukan terhadap sifat ketahanan pukul dan kekerasan.

Ketahanan pukul merupakan sifat benda terhadap daya absorbsi energi pukulan yang menggunakan alat Universal Impact tester dengan metode pengujian SII $0673-82$.

Kekerasan merupakan sifat benda terhadap tusukan, indikator jarum yang menunjukkan skala tertentu yang menggunakan alat shore Durometer dengan metode pengujian SIl $0511-81$.

Sebelum diuji cuplikan yang sudah dipotong dimasukkan dalam ruang pemantapan (conditioning room) sesuai dengan SII $1098-84$.

\section{HASIL PENELITIAN DAN PEMBAHASAN}

Perbandingan campuran HDPE dan riklim polietilen ada lah dari $0 \%$ HDPE dengan 100\% riklim PE sampai dengan $100 \%$ HDPE dengan $0 \%$ PE, seperti terlihat pada tabel 1 : 
Tabel I : Komposisi campuran riklim PE dengan HDPE ( dalam prosentase)

\begin{tabular}{c|r|c}
\hline No. urut & HDPE & Riklim $/$ Polietilen \\
\hline 1. & 0 & 100 \\
2. & 10 & 90 \\
3. & 20 & 80 \\
4. & 30 & 70 \\
5. & 40 & 60 \\
6. & 50 & 50 \\
7. & 60 & 40 \\
8. & 70 & 30 \\
9. & 80 & 20 \\
10. & 90 & 10 \\
11. & 100 & 0 \\
\hline
\end{tabular}

1. Hasil Pengujian Kekerasan.

Hasil uji kekerasan untuk masing-masing komposisi dapat dilihat pada tabel 2 .

Tabel 2 : Hasil uji Kekerasan (shore D).

\begin{tabular}{c|c|c|c|c|c|c|c|c}
\hline \multirow{2}{*}{$\begin{array}{c}\text { No. } \\
\text { urut }\end{array}$} & \multicolumn{7}{|c|}{ Komposisi } & \multicolumn{5}{|c|}{ Ulangan } & \multirow{2}{*}{ Rata-rata. } \\
\cline { 2 - 7 } & HDPE & RPE & I & II & III & IV & V & \\
\hline 1. & 0 & 100 & 63 & 63 & 64 & 63 & 63 & 63,2 \\
2. & 10 & 90 & 63 & 63 & 63 & 63 & 64 & 63,2 \\
3. & 20 & 80 & 63 & 63 & 63 & 63 & 64 & 63,2 \\
4. & 30 & 70 & 63 & 63 & 64 & 63 & 64 & 63,4 \\
5. & 40 & 60 & 64 & 64 & 64 & 64 & 64 & 64,0 \\
6. & 50 & 50 & 63 & 64 & 63 & 63 & 63 & 63,2 \\
7. & 60 & 40 & 63 & 64 & 63 & 63 & 63 & 63,2 \\
8. & 70 & 30 & 64 & 64 & 64 & 64 & 64 & 64,0 \\
4. & 80 & 20 & 63 & 63 & 63 & 63 & 64 & 63,2 \\
10. & 90 & 10 & 64 & 64 & 64 & 64 & 64 & 64,0 \\
11. & 100 & 0 & 64 & 64 & 64 & 64 & 64 & 64,0 \\
\hline
\end{tabular}

Dari tabel 2 didapat persamaan regresi linier $Y=63,16+$ $0,007 \times$ untuk membuktikan apakah regresi linier diterima atau ditolak dilakukan analisa variasi dan koefision korelasi untuk komposisi dengan hasil uji kekerasan.
Tabel 3: Analisa untuk regresi $Y=63,16+0,007 x$

\begin{tabular}{|c|c|c|c|c|c|}
\hline Variasi & dk & $J K$ & RJK & F.Hitung & F.Tahel \\
\hline Regresi (a) & 1 & $8.873,49$ & $8.873,49$ & - & $\bar{s}$ \\
\hline Regresi $(a / b)$ & 1 & 19,61 & 19,61 & 0,029 & 4,05 \\
\hline Kesalahan & 53 & $35.474,00$ & 669,34 & - & - \\
\hline Total & 55 & $44.368,10$ & - & - & - \\
\hline
\end{tabular}

Dari tabel 3 diambil taraf signifikasi $P$ 0,05 tampak bahwa $F$ hitung lebih kecil dari $F$ tabel $(F+a b \mid \geq F$ hit) jadi bentuk linier ditolak.

Hasil perhitungan koefisien korelasi antara komposisi dengan hasil uji kekerasan untuk menentukan korelasi $Y$ dan $x$ adalah $r=0,58$. Dengan demikian dikatakan $33,64 \%\left(r^{2} \times 100 \%\right)$ kecenderungan variasi dalam y dapat dijelaskan oleh $x$, kecenderungan ini sangat lemah untuk menjelaskan $y$ dengan persamaan $y=63,66+0,007 x$.

Dengan demikian komposisi dan variasi $x$ tidak mempengaruhi kekerasan komposisi. Ini dapat dilihat pada tabel 2, kekerasan terletak antara 63,2 - 64,0 shore $D$ dengan rata-rata kekerasan 63,51 shore D dan standard deviasi 0,39. (Lihat grafik 1).

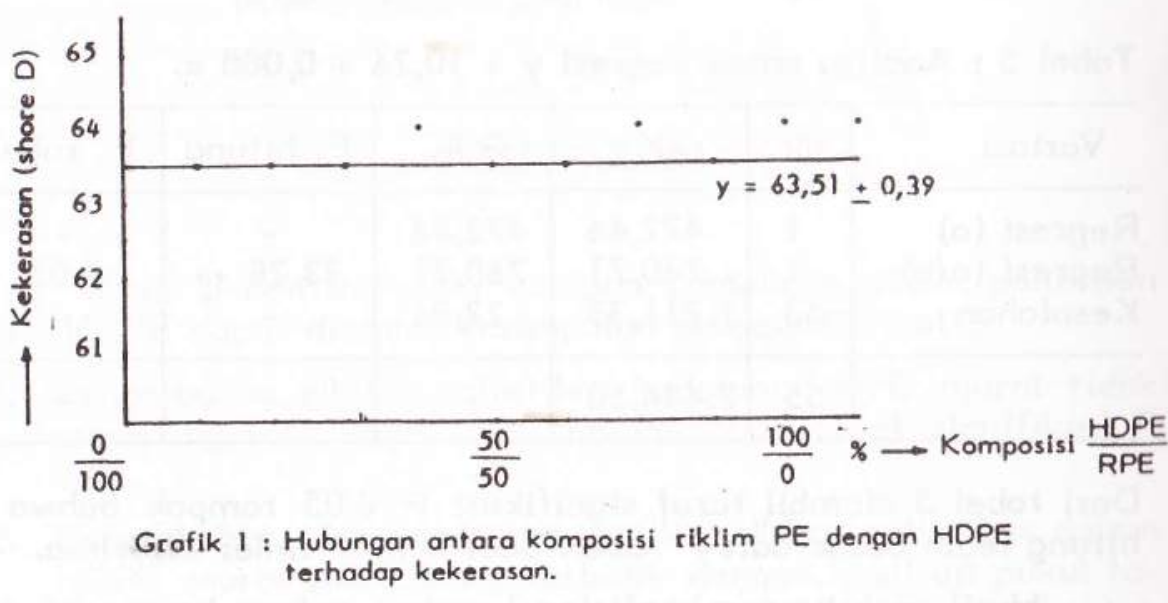

Vol.IV.No.8-1988/1989 
2. Hasil Uji Ketahanan Pukul Takik $(\mathrm{kg} \mathrm{cm} / \mathrm{cm})$.

Hasil uji ketahanan pukul takik untuk masing-masing komposisi dapat dilihat dalam tabel 4 .

Tabel 4 : Hasil uji Ketahanan pukul takik $(\mathrm{kg} \mathrm{cm} / \mathrm{cm})$.

\begin{tabular}{c|c|c|c|c|c|c|c|c}
\hline \multirow{2}{*}{$\begin{array}{c}\text { No. } \\
\text { urut }\end{array}$} & \multicolumn{6}{|c|}{ Komposisi } & $\begin{array}{c}\text { Ulangan } \\
\text { Rata- } \\
\text { rata }\end{array}$ \\
\cline { 2 - 9 } & HDPE & RPE & I & II & III & IV & V & \\
\hline 1. & 00 & 100 & 10,23 & 10,34 & 9,76 & 10,65 & 10,65 & 10,33 \\
2. & 10 & 90 & 11,83 & 10,31 & 10,55 & 11,90 & 11,41 & 11,20 \\
3. & 20 & 80 & 12,63 & 12,78 & 11,03 & 12,10 & 12,07 & 12,12 \\
4. & 30 & 70 & 12,28 & 12,83 & 13,70 & 12,18 & 12,25 & 12,65 \\
5. & 40 & 60 & 13,45 & 13,58 & 13,96 & 14,45 & 13,69 & 13,83 \\
6. & 50 & 50 & 14,41 & 14,41 & 14,66 & 14,32 & 14,37 & 14,43 \\
7. & 60 & 40 & 14,62 & 16,69 & 15,22 & 15,30 & 14,95 & 15,36 \\
8. & 70 & 30 & 16,77 & 16,15 & 16,18 & 16,47 & 16,35 & 16,38 \\
9. & 80 & 20 & 18,32 & 16,53 & 18,08 & 17,76 & 16,70 & 17,48 \\
10. & 90 & 10 & 17,67 & 19,30 & 18,64 & 18,02 & 18,93 & 18,51 \\
11. & 100 & 0 & 18,08 & 18,98 & 18,93 & 19,61 & 18,93 & 18,91 \\
\hline
\end{tabular}

Dari tabel diatas didapat persamaan regresi linier $y=$ $10,26+0,088 x$

Untuk membuktikan apakah regresi linier yang dapat diterima, dilakukan analisa variasi dan koefisien korelasi antara komposisi dengan hasil uji ketahanan pukul takik.

Tabel 5 : Analisa untuk regresi $y=10,26+0,088 x$.

\begin{tabular}{l|r|c|c|c|c}
\hline Variasi & dk & JK & RJK & F. hitung & F. tabel \\
\hline $\begin{array}{l}\text { Regresi }(a) \\
\text { Regresi }(a / b)\end{array}$ & 1 & 472,46 & 472,46 & - & - \\
Kesalahan & 53 & $\begin{array}{r}760,71 \\
711,33\end{array}$ & $\begin{array}{c}760,71 \\
22,86\end{array}$ & $33,28++$ & - \\
\hline & 55 & $2.444,50$ & - & - & - \\
\hline
\end{tabular}

Dari tabel 5 diambil taraf signifikasi $P$ 0,05 tampak bahwa $F$ hitung lebih besar dari $\mathrm{F}$ tabel. Jadi bentuk linier diterima.

Hasil perhitungan koefisien korelasi antara komposisi dengan hasil uji untuk menentukan korelasi $y$ dan $\times$ adalah $\tau=$
0,998. Dengan demikian dikatakan $99,60 \%\left(r^{2} \times 100 \%\right)$ kecenderungan variasi dalam $y$ dapat dijelaskan oleh $x$ melalui persamaan regresi linier $y=10,26+0,088 x$.

Dengan demikian komposisi dan variasi $x$ mempengaruh ketahanan pukul takik kompon. Ini dapat dilihat pada grafik 2 .

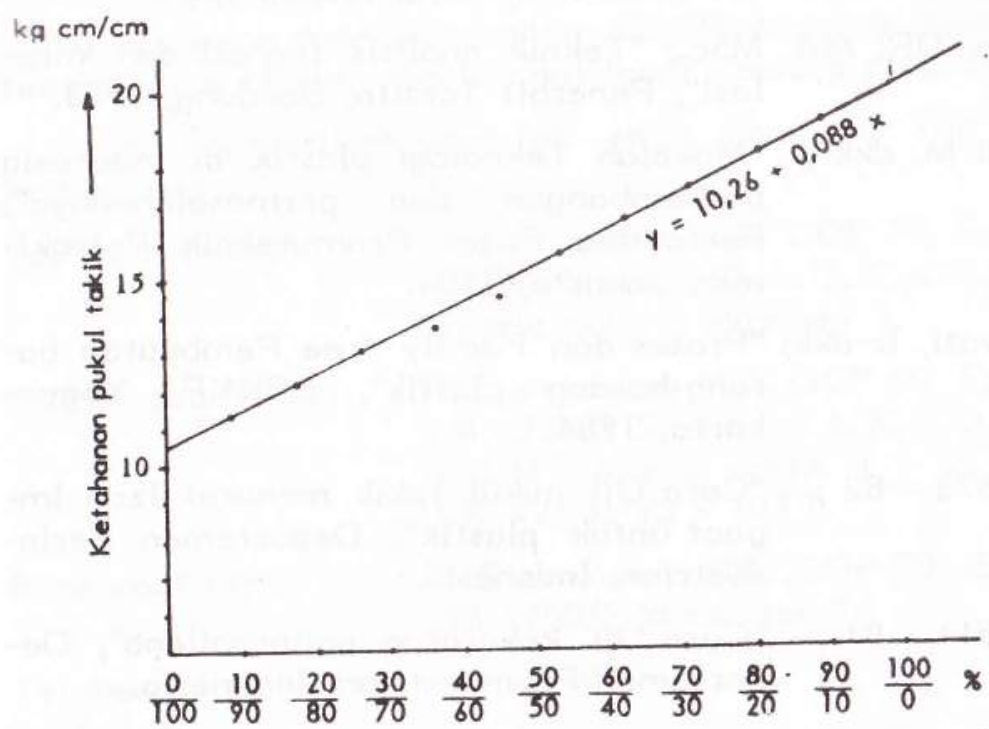
Grafik 2 : Hubungan antora komposisi riklim PE dengan HDPE
terhadap ketahanan pukul takik. Komposisi $\frac{\mathrm{HDPE}}{\mathrm{RPE}}$

\section{KESIMPULAN}

Hasil penelitian sifat kompon campuran riklim polietilen dan HDPE dapat diambil kesimpulan sebagai berikut :

Penambahan riklim polietilen kedalam HDPE murni tidak mempengaruhi kekerasan kompon pada taraf signifikasi $P$ 0,05 .

2. Penambahan dan penurunan jumlah riklim polietilen dalam HDPE murni berbanding terbalik dengan hasil uji pukul ta.kik kompon pada taraf signifikasi $P$ 0,05 yang membentuk persamaan linier $Y=10,26+0,088 x$. 


\section{DAFTAR PUSTAKA}

1. Hubery, H. ; "Plastic Physical Technology", LKT TGM Wien, 1980.

2. Richardson, Terry A; "Modern Industrial Plastics", Howard, W. Sams \& Co. INC Indian, 1974.

3. Sudjana, DR. MA. MSc.; "Teknik analisis regresi dan korelasi", Penerbit Tarsito, Bandung, 1983.

4. Sugandi M, dkk; "Makalah Teknologi plastik di Indonesia perkembangan dan permasalahannya", Pertamina Pusat Pramuteknik Petrokimia, Jakarta, 1984.

5. Susilowati, Ir dkk; "Proses dan Family tree Pembuatan barang-barang plastik", BBKKP, Yogyakarta, 1984.

6. SII - $0673-82$; "Cara Uji pukul takik menurut Izod Impact untuk plastik", Departemen Perindustrian, Indonesia.

7. SII - 0511-81; "Cara Uji kekerasan polipropilena", Departemen Perindustrian, Indonesia. 